\title{
FOTOGRAFIA COLONIAL: MATERIALIDADES E IMATERIALIDADES IDENTITÁRIAS NO CONTEXTO PORTUGUÊS
}

\author{
Liliana Oliveira da Rocha ${ }^{1}$ \\ Patrícia Ferraz de Matos $^{2}$
}

\begin{abstract}
Resumo
O presente artigo reflete sobre o lugar da fotografia colonial no contexto patrimonial nacional português. Indagando sobre o modo como se processam os fenómenos de musealização, catalogação e atribuição de valor patrimonial a certos bens/objetos, explanase sobre o que é legislado e institucionalizado por organismos do poder político, bem como sobre a sua influência na construção das narrativas identitárias e na patrimonialização dos legados coloniais. Com base nas resoluções legislativas, procura-se, assim, averiguar o que tem sido celebrado e salvaguardado em detrimento daquilo que tem sido apagado. Neste âmbito, dá-se particular atenção à fotografia, com o intuito de tentar perceber que futuro e que lugar poderão ter as imagens produzidas em contexto colonial nos museus nacionais.
\end{abstract}

Palavras-chave: património; fotografia; identidade; colonialismo

\section{COLONIAL PHOTOGRAPHY: IDENTITY MATERIALITIES AND IMMATERIALITIES IN THE PORTUGUESE CONTEXT}

\begin{abstract}
The current article is a reflection about the role of the colonial photography in the Portuguese's national heritage context. Inquiring about how the process of musealization occurs, as well as the cataloging and the assignment of heritage value of certain belongings/objects, it reflects on what is legislated and institutionalized by the bodies of political power and about their influence in the construction of national identities and patrimonialization of colonial legacies. Based in these legislative resolutions, it searches for what has been celebrated and preserved against what has been erased. In this context, it focuses on photography, with the objective to understand which future and place have the images that were produced during the colonial period in the Portuguese's museums.
\end{abstract}

Key words: heritage; photography; identity; colonialism

\footnotetext{
${ }^{1}$ Instituto de Ciências Sociais da Universidade de Lisboa, Av. Prof. Aníbal de Bettencourt, 9, 1600-189 Lisboa, lilianaorocha@ics.ulisboa.pt (Bolseira da Fundação para a Ciência e a Tecnologia: SFRH/ $\mathrm{BD} / 140562 / 2018)$.

2 Instituto de Ciências Sociais da Universidade de Lisboa, Av. Prof. Aníbal de Bettencourt, 9, 1600-189 Lisboa, patricia matos@ics.ulisboa.pt (Bolseira da Fundação para a Ciência e a Tecnologia: SFRH/BPD/91349/2012).

Criar Educação, Criciúma, v. 7, n², jul/dez 2018.- PPGE - UNESC
} 


\section{Introdução}

$\mathrm{Na}$ aceção do antropólogo Ricardo Vieira, o património pode ser definido como um conjunto de "ideias e objectos com os quais as sociedades afirmam as suas diferenças perante os outros" (Vieira, 2005, p. 8). Intrinsecamente ligado à identidade, o património autodefine-se, nesse sentido, como a materialidade e a imaterialidade de uma identidade coletiva.

De acordo com esta aceção, vale a pena introduzir uma enunciação do antropólogo Arjun Appadurai, que se revelou preponderante em todas as questões que se foram colocando ao longo deste trabalho de investigação e refletem sobre os perigos de pensar as identidades e as culturas a partir de princípios substancialistas ou essencialistas. Segundo o autor:

(...) não vale a pena encarar a cultura como substância; é melhor encará-la como uma dimensão dos fenómenos, uma dimensão que releva da diferença situada e concretizada. Salientar este dimensionamento da cultura em vez da sua substancialidade permite-nos pensar a cultura não tanto como propriedade dos indivíduos e grupos, mas como um instrumento heurístico ao nosso alcance para falarmos de diferença (Appadurai apud Vieira, 2005, p. 8).

Inspirado nesta reflexão, o presente trabalho de investigação dedicou-se a analisar as relações entre memória, identidade nacional e património, procurando perceber: como se processam os fenómenos de musealização, catalogação e atribuição de valor patrimonial a certos bens/objetos; o que legislam e institucionalizam os órgãos do poder político em questões patrimoniais; que tratamento têm as matérias coloniais em Portugal; e que valor e utilidade tem hoje a fotografia produzida no contexto colonial.

O artigo compreende, assim, quatro tópicos que refletem sobre: 1) o enquadramento legislativo do património cultural e a respetiva materialização da identidade nacional; 2) os processos de musealização dos bens culturais (materiais e imateriais); 3) a construção das narrativas identitárias e a dificuldade de musealizar os legados do colonialismo; 4) a fotografia colonial, em particular, e o lugar que esta deve ocupar nos museus.

Criar Educação, Criciúma, v. 7, n², jul/dez 2018.- PPGE - UNESC 


\section{1 - Enquadramento legislativo do património cultural e materialidade e imaterialidade da identidade}

Em Portugal, o enquadramento normativo e institucional em matéria de Património Cultural Imaterial é relativamente recente. Seguindo as orientações de organismos internacionais (Conselho da Europa, ICOMOS, Unesco) na redefinição do seu quadro legislativo, o país inclui, pela primeira vez, a noção de elementos imateriais associados ao património cultural em 1985 (Lei no 13/85). Apesar de constituir um passo importante, este diploma limita-se unicamente a introduzir o tema. Somente em 2001, o panorama geral sobre o património cultural viria a sofrer alterações com a Lei n. ${ }^{107 / 2001}$, de 8 setembro. Uma nova definição para património cultural é então patenteada, sendo o conceito amplamente alargado com a inclusão de várias referências a bens imateriais (especialmente no ponto 4 e 6). Com esta lei, o enquadramento legislativo do património cultural altera-se significativamente em Portugal. Reconhecendo a importância da proteção do património cultural, como algo de preponderante na construção da identidade nacional e na democratização da cultura, o Estado português procura redefinir as bases políticas referentes a esta matéria, no intuito de "assegurar a transmissão de uma herança nacional cuja continuidade e enriquecimento unirá as gerações num percurso civilizacional singular" (PGDL, 2001, s/p).

Deste modo, no Art. 2 é apresentada uma nova definição para o conceito de património cultural que visa contemplar "todos os bens com valor de civilização" ou "portadores de interesse cultural relevante": a língua portuguesa; bens que reflitam "valores de memória, antiguidade, autenticidade, originalidade, raridade, singularidade ou exemplaridade"; bens imateriais "que constituam parcelas estruturantes da identidade e da memória colectiva portuguesas"; e a cultura tradicional popular (PGDL, 2001, s/p).

Em 2009, a lei de 2001 é revista com o intuito de emparelhar as resoluções da Convenção para a Salvaguarda do Património Cultural Imaterial adotadas na 32. ${ }^{\text {a }}$ Conferência Geral da Unesco. Reiterando alguns dos considerandos anteriores, o Criar Educação, Criciúma, v. 7, n², jul/dez 2018.- PPGE - UNESC 
presente diploma estabelece para a imaterialidade do património português os seguintes domínios:

a) Tradições e expressões orais, incluindo a língua como vector do património cultural imaterial; b) Expressões artísticas e manifestações de carácter performativo; c) Práticas sociais, rituais e eventos festivos; d) Conhecimentos e práticas relacionados com a natureza e o universo; e) Competências no âmbito de processos e técnicas tradicionais (Diário da República, 15 de junho de 2009, p. 3648).

Apesar dos parâmetros legislativos e daquilo que é convencionado institucionalmente, considera-se amiúde que "património cultural é o nosso rosto"; são "pedaços da nossa identidade"; é "a memória de uma trajectória comum" (Pacheco, 1987,p. 13).

A materialidade da identidade concretiza-se, não raras vezes, no património. Este último e a identidade são, assim, dois conceitos intimamente relacionados, entendendo-se a identidade como a "essência" de um determinado coletivo humano; e o património como a sua manifestação "natural", que sobrevive ao decurso do tempo e que é preciso resgatar e preservar (Peralta e Anico, 2006, p. 1).

Mas, como apontam as antropólogas Elsa Peralta e Marta Anico, estas conceções fixistas e essencialistas de identidade e património, veiculadas pelas instituições e pelos órgãos governamentais, têm naturalmente um forte pendor político e remetem para os nacionalismos modernos. Atente-se nas palavras de Peralta:

\begin{abstract}
O património é sempre uma autodefinição cultural, materializada em estandartes públicos, que se fundamenta no passado e numa especificidade etnocultural, cujos elementos são articulados de forma arbitrária para servir o projecto colectivo, sendo que esse projecto é definido, as mais das vezes, por propostas de cunho ideológico emanadas das esferas políticas (2003, p. 86).
\end{abstract}

Neste contexto, a nostalgia do passado e o culto da memória, por oposição à globalização do mundo contemporâneo e a uma "ameaça" de homogeneização cultural, parecem conduzir a uma asseveração das identidades regionais e nacionais e a uma consequente focalização na sua história e na sua "especificidade". A busca pela memória é, assim, uma busca pela afirmação das 
suas identidades (Peralta e Anico, 2009, p. 3).

Neste sentido, o património, enquanto forma de objetivação de identidades, providencia uma série de "totens", isto é, símbolos identitários unificadores, com os quais os indivíduos se identificam. Contudo, segundo as autoras, tais "totens" repetida e abusivamente instrumentalizados, tal como o passado ou o património de uma comunidade, incorrem no perigo de se desvirtualizarem, dando origem a identidades "banais e vazias" (Peralta e Anico, 2009, p. 1).

Numa era em que os cidadãos necessitam mais do que uma bandeira para se identificarem e clamam por referências capazes de traduzir a sua alma coletiva, urge, segundo Peralta e Anico, tanto um comprometimento com o passado, como uma "demissão" do mesmo (2009, p. 1).

\section{2 - Musealizar o mundo}

O património constrói-se a partir da musealização do mundo, que acontece a partir de um conjunto de atos deliberados nos quais intervêm vários agentes culturais e políticos, cuja finalidade é selecionar e preservar aquilo que se pensa caracterizar uma determinada sociedade, numa tentativa de recoleção de símbolos identitários que deverão perdurar ao longo do tempo.

O antropólogo Fernando Magalhães, debruçando-se sobre o conceito de musealização, tece as seguintes considerações a respeito do mesmo:

\footnotetext{
O processo de musealização consiste na metamorfose de objectos que, não deixando de ter valor social e cultural, adquirem outro, mais especial, com a nova recontextualização. Trata-se de um caminho que consiste em transformar objectos materiais e imateriais, aparentemente vulgares, em legados históricos ou testemunhos de desenvolvimento científico, técnico, artístico ou outro de uma determinada cultura e, nesse sentido, eles iniciam uma fase simbólica de representação da comunidade $(2005$, p. 11).
}

Segundo o filólogo Andreas Huyssen, "não há dúvida que o mundo está sendo musealizado (...) como se o objectivo fosse conseguir a recordação total" (2000, p. 15). Contudo, essa musealização global faz-se a partir de alguns parâmetros que distinguem o que fica dentro do que fica fora. Sendo o património 
um conjunto de objetos e elementos "sob os quais se funda a identidade de um grupo" (Magalhães, 2005, p. 11), torna-se eminente então explanar sobre quem decide o quê no processo de patrimonialização.

Num artigo intitulado "Património e Identidade - Os Desafios do Turismo Cultural", Elsa Peralta levanta questões pertinentes acerca do modo como as sociedades legam e recebem bens patrimoniais. Segundo a autora, o património não pode ser reduzido aos "vestígios tangíveis do processo histórico", uma vez que a herança patrimonial é um processo dinâmico no qual intervêm as escolhas e seleções "conscientes" de um grupo significativo de indivíduos com vontade de legar determinados bens culturais às gerações futuras (2000, p. 218). Observe-se a sua enunciação:

Aquilo que é ou não é património, depende do que, para um determinado colectivo humano e num determinado lapso de tempo, se considera socialmente digno de ser legado a gerações futuras (Peralta, 2000, p. 218).

Deste modo, Elsa Peralta assevera que o património é um conceito relativo, que depende da subjetividade de quem atribui valor aos objetos, e por isso "permeável às flutuações da moda e aos critérios de gosto dominantes", sendo "matizado pelo figurino intelectual, cultural e psicológico de uma época" (2000, p. 218). Aquilo que é ou não legado às gerações vindouras, de acordo com as elucidações da autora, depende, assim, dos juízos de valor de uma determinada coletividade num certo decurso de tempo.

Neste sentido, conclui-se que toda a construção patrimonial é fruto da capacidade de uma comunidade se autorrepresentar simbolicamente e, por conseguinte, de uma identidade "manufaturada" e idealizada" (Peralta, 2000, p. 218).

Por sua vez, na introdução da obra Heritage and Identity, Elsa Peralta e Marta Anico afirmam que o património está ainda estreitamente relacionado com as questões de poder e a escolha de recordar ou esquecer certos aspetos do passado está intrinsecamente ligada a políticas de identidade (2009, p. 1). O património preserva ou renega, assim, os eventos do passado consoante os desígnios do presente.

Criar Educação, Criciúma, v. 7, n², jul/dez 2018.- PPGE - UNESC 
Na aceção das autoras, ativado pelo poder político, o património visa, através do recurso à memória coletiva, a legitimação simbólica das ideologias veiculadas pelo Estado. Nesse sentido, para Peralta e Anico, muitas vezes o património é uma recriação histórica que serve mitos, ideologias nacionalistas e crenças, e procura promover a coesão social e legitimar as instituições de onde provêm tais mitos (2009, p. 25).

O antropólogo Llorenç Prats entende também o património como uma ativação de referentes patrimoniais que se transformam em representações simbólicas da identidade. É legítimo, neste sentido, afirmar que o património é então uma construção, ou uma ativação, e que o principal agente de ativação patrimonial é o poder político, pois é ele o "principal construtor de museus, parques naturais e arqueológicos, catálogos de monumentos e identidades" (Prats, 1997, p. 34). "Sem poder", declara Prats, "poderíamos dizer que não existiria património" (1997, p. 35), pelo menos oficializado. É verdade que existem outros agentes sociais e culturais, no entanto tais agentes, para poderem "ativar" os seus reportórios patrimoniais, necessitam sempre do suporte político (pelo menos para os verem institucionalmente reconhecidos).

Fernando Magalhães, por sua vez, defende que o património foi-se tornando "ao longo de uma modernidade caracterizada pelo efémero, pela produção e destruição acelerada de bens de consumo, num veículo de transmissão, conservação e reprodução da memória social, considerada fundamental para legitimar a ordem social presente" (2005, p. 22). Questionando-se sobre a legitimidade dos universos patrimoniais e identitários nacionalmente construídos, o autor assevera que, hoje, não se pode falar de uma única identidade pessoal ou cultural, porque as identidades são "fragmentadas e mutáveis dentro de si mesmas" (Magalhães, 2005, p. 29). Considere-se a exposição do professor:

Se durante todo o período compreendido entre o século XVI e meados do século XX era o contexto social e cultural com as suas normas e valores que influenciava a construção da identidade pessoal, onde havia pouco espaço para a individualidade, ao contrário do que a modernidade prometia, (...) [hoje] a questão central não está em saber se existe ou não identidade, mas se é possível atribuir uma identidade a todo um grupo, sem ter em conta as visões que os actores sociais desse grupo têm acerca de si e do seu próprio espaço de pertença, que pode ser geográfica e coincidente com

Criar Educação, Criciúma, v. 7, n², jul/dez 2018.- PPGE - UNESC 
o de outros indivíduos ou não (...). Assim, não se pode falar numa identidade pessoal ou cultural, mas em várias identidades, em que as sociedades actuais reconhecem as múltiplas identidades fragmentadas e mutáveis dentro de si mesmas (...). Os sujeitos são livres de escolher quem querem "ser", e com quem se querem identificar" (Magalhães, 2005, pp. 27-29).

De facto, se durante a modernidade as sociedades e os Estados-Nação "necessitaram de âncoras no passado, como o património, que lhes permitiam estabilidade e sobrevivência" (não interessando "se essas âncoras representavam um discurso identitário baseado na procura das verdadeiras raízes, ou se, o que é mais verdade, essas 'raízes' eram inventadas ou (re)inventadas", hoje, as sociedades plurais, múltiplas e em constante mutação demandam outras narrativas identitárias (Magalhães, 2005, p. 30).

Todavia, num contexto mundial de globalização o que se verifica é um renascer das identidades nacionais, locais, regionais ou comunitárias, pois "perante o contacto decorrente desta transnacionalização de pessoas, capitais, ideias e bens, as comunidades locais tomam consciência de si enquanto grupo partilhando de valores comuns" (Magalhães, 2005, p. 30). Segundo Magalhães, a diferença entre a modernidade e o mundo contemporâneo prende-se então com o facto de atualmente se empreender uma "renovada leitura simbólica do património e dos objectos que o compõem", tratando-se, por isso, "sobretudo de um processo arbitrário e temporal" (2005, p. 30).

A Segunda Guerra Mundial, e consequente destruição do património cultural edificado na Europa, conduziu ao aparecimento da Unesco, em 1946; no entanto, é nas décadas de 60 e 70 que o conceito de património se democratiza, "em resposta às consequências de uma modernidade que o viu nascer" (Magalhães, 2005, p. 30). Doravante, os objetos e bens patrimoniais que incorporam "marcas únicas de um artesão, de uma região, de uma época ou de um contexto social-histórico particular" passam a ser empreendidos na "reivindicação de identidades locais e específicas" (Magalhães, 2005, p. 31).

Refletindo sobre o processo de "metamorfosear" certos bens em património, Magalhães elucida que a catalogação ou "invenção" do património material e imaterial, além de não estar imune às relações de poder e de "quem decide se é

Criar Educação, Criciúma, v. 7, n², jul/dez 2018.- PPGE - UNESC 
património ou não", recorre frequentemente a um "passado grandioso" que permite às comunidades distinguirem-se das demais num mundo cada vez mais globalizado (2005, pp. 30, 12, 22). Atente-se na sua enunciação:

[O] investimento [em matérias patrimoniais] é feito em nome de um tempo sem tempo e de um espaço sem espaço, onde a cultura material e imaterial, particular de uma comunidade, parece simbolizar um passado grandioso sobre o qual assenta a identidade presente dessa comunidade e lhe permite fazer face aos crescentes fluxos provenientes de outras sociedades e culturas, e que decorrem do processo de globalização acelerado que se vive no século XXI (2005, p. 22).

De facto, perante a crescente globalização e a necessidade de afirmação de uma identidade local, o processo de patrimonialização e seleção de elementos materiais e imateriais a serem legados às gerações futuras, tende a ancorar-se numa espécie de passado "glorioso", procurando coroar a especificidade das sociedades com base na sua "grandiosidade" passada.

\section{3 - Musealizar o colonial}

O historiador David Lowenthal afirma que "as nações são únicas, não só no que escolhem para relembrar, mas também no que se sentem obrigadas a esquecer" (1994, p. 50). Partindo deste mote, e corroborando a afirmação do autor, importa questionar o que em Portugal tem sido relembrado e o que tem sido esquecido.

Neste sentido, relativamente ao período colonial, o historiador Michel Cahen defende que "o que foi condenado com o salazarismo foi bem mais o seu colonialismo como política, do que a colonização como obra", subsistindo, por isso, nas sociedades atuais conceitos como "lusitanidade" e "império" que sobreviveram "perfeitamente à descolonização" (2013, p. 298). À luz de tal consideração talvez se consiga compreender, por exemplo, o motivo pelo qual Portugal celebra "naturalmente" os 600 anos da tomada de Ceuta, mas é impelido a transladar a coleção (inteira) do Museu de Arte Popular (MAP) para o Museu Nacional de Etnologia. O filósofo Eduardo Lourenço sustenta a este respeito que uma existência mítica precede a existência empírica portuguesa, defendendo, deste modo, que

Criar Educação, Criciúma, v. 7, n², jul/dez 2018.- PPGE - UNESC 
toda a leitura do nosso passado encontra-se ancorada nas Descobertas (2005, p. 35).

Segundo o sociólogo Albertino Gonçalves, "os discursos de identidade tendem a suspender ou a exorcizar a negatividade" e "tanto a hetero-identificação, que categoriza o outro, como a auto-identificação, que reconhece o semelhante, diluem e atropelam a diversidade" (2009, p. 61). Socialmente construídas, as identidades nacionais são, assim, para o autor, essencialistas e sempre polémicas, pois "envolvem bricolages ideológicos" (2009, p. 63). Na sua aceção, essências como a "lusitanidade", ou a "portugalidade", absolutizam o que é relativo e substantivam o que é relacional, fundamentando "na natureza ou no mito o que é histórico" (2009, p. 63). Relativas e questionáveis, as propostas identitárias tendem, deste modo, a "converter-se, pela fé e pela crença, em princípios absolutos" (Gonçalves, 2009, p. 63).

Já para o sociólogo Ronaldo Ortiz, "a invariância (imutável) da identidade coincide com a univocidade do discurso nacional" (2006, p. 3). Neste sentido, e na aceção da historiadora Françoise Choay, o património atesta a monoculturalidade das identidades nacionais, subsistindo como a "garantia das origens" (1992, p. 16).

Efetivamente, existe um pendor associado ao património que tende a remetêlo para o lado "autêntico" ou originário das sociedades, relegando o seu caráter vivo e dinâmico. Tal tendência revela-se contraditória à mutabilidade e transitoriedade das identidades (quer individuais, quer colectivas). Na verdade, se as identidades são voláteis e constantemente atualizáveis no quotidiano das comunidades, os objetos patrimoniais (e tudo aquilo que se decide patrimonializar) devem ser capazes de acompanhar a mutação das identidades, recontextualizando-se e adquirindo novos e atuais significados.

\section{1 - 0 caso da fotografia}

Quando se pensa em património, pensa-se, de facto, em algo vivo e dinâmico que espelhe uma identidade própria. A historiadora Isabel Castro Henriques assevera, por isso, que conhecer o nosso património implica não só o estudo das 
muitas heranças que nos foram deixadas por todos aqueles que se instalaram em Portugal, como também uma análise "da maneira como as vimos e vemos, as quisemos e queremos, as integrámos e integramos” (2001, p. 14). Segundo a autora, "a herança não é apenas aquilo que os outros nos transmitem, mas o que nós elaboramos a partir dos elementos que recebemos ou julgamos receber, isto é, da forma como os interpretamos" (Henriques, 2001, p. 14).

Neste contexto, a fotografia enquanto testemunha, fonte de memória, relato documental e histórico com um valor patrimonial latente, pode revelar-se profícua para uma análise sobre o modo como nos relacionamos com o passado e afirmamos as nossas identidades. As imagens fotográficas convocam e evocam memórias, muitas vezes longínquas, trazendo-as para o presente e possibilitando a (re)visitação de histórias de outrora. Na aceção do historiador Pierre Nora, é possível afirmar que elas constituem "lieux de mémoire" (1989, p. 7), onde o tempo e a história se cristalizaram e se produz uma ilusão de eternidade.

Não obstante, segundo o fotógrafo e historiador Boris Kossoy, todo o registo fotográfico tem uma intencionalidade (2001, p. 39) e, nesse sentido, parecem não restar dúvidas de que a fotografia colonial, amiúde, seguiu os ímpetos e os desígnios imperialistas e colonialistas de um determinado período. Dentro de um quadro de exaltação da heroicidade quimérica de um povo "originalmente marítimo" (Cunha, 2007, p. 194), com uma missão e um devir históricos, uma vocação ecuménica e um "génio civilizador", que o deveria levar a colonizar e evangelizar outros povos ("inferiores", "selvagens" e "primitivos") "do Minho a Timor", as fotografias coloniais revelam, naturalmente, a "grandeza" do povo português (e dos seus feitos) em detrimento de África e do povo africano.

Colocada ao serviço de propaganda dos organismos oficiais do Estado, a fotografia procurou disseminar uma "identidade imperial" mostrando um país pluricontinental e "multirracial", bem como uma imagem estereotipada de África e do "outro" (todo aquele que não é branco, nem europeu), reduzindo-o a um ser incivilizado e profano (Cunha, 2007, p. 194).

Posto isto, deverá a fotografia produzida em contexto colonial (muitas vezes comissionada pelo governo português e responsável por ter ajudado a criar Criar Educação, Criciúma, v. 7, n², jul/dez 2018.- PPGE - UNESC 
simbolicamente uma nação imperial - mediante a propagação de ícones, mitos, sentimentos e memórias imperiais -, bem como por ter contribuído para alterar o modo como os portugueses se viam a si próprios e aos outros) ser arrumada numa gaveta, ou trabalhada e envergada pelos museus e instituições na criação de novos imaginários? Num artigo intitulado "How societies remember the past?", o sociólogo John Urry, procurando responder a estes entrançados entre memória e identidade, afirma que o passado é incessantemente construído e reconstruído no e através do presente (1996, p. 48). Neste sentido, talvez importe um olhar mais profundo sobre a patrimonialização do passado colonial e os clichês ${ }^{3}$ da identidade, através da fotografia.

Segundo Vieira, "os objectos também falam" (2005, p. 8). Partindo desta constatação, coloca-se a pergunta: De que nos falam as fotografias coloniais?

Os estados europeus, cientes das capacidades reprodutivas "realistas" das imagens fotográficas ${ }^{4}$, cedo convocaram a nova arte mecânica para o seu serviço, instrumentalizando-a na edificação dos seus projetos colonialistas, especialmente durante a "corrida para África", no final do século XIX. Deste modo, rapidamente, as metrópoles ocidentais povoaram-se de publicações de imagens de temática colonial que permitiam aos seus cidadãos sonhar e imaginar um "império" através de imagens política e ideologicamente selecionadas. Baseadas numa relação de dominância e tentativa de conquista da África desconhecida, estas imagens retratam paisagens "maravilhosas", aspetos de vida "característicos" das populações autóctones e elementos denunciadores da presença portuguesa nas colónias. São sobretudo "os rostos, masculinos, da exploração geográfica e científica do continente africano, assim como das personalidades da ocupação militar, da ação governativa e da vida religiosa (...) que dotavam o império e os seus diferentes agentes de uma fisionomia"; e a ideia de uma "África romântica e aprazível, de um território repleto de potencialidades económicas ainda pouco

3 "Clichê", em linguagem fotográfica, significa "chapa negativa". Vulgarmente denominado de "negativo", o "clichê" permite a reprodução de várias provas a partir da mesma matriz, daí a sua apropriação para designar "chavões" e tudo o que se repete.

${ }^{4}$ Sobre os poderes da fotografia no sentido de dizer a "verdade", manipular, encenar e ver além do visível, veja-se Rocha \& Matos, 2018.

Criar Educação, Criciúma, v. 7, n², jul/dez 2018.- PPGE - UNESC 
explorado e de uma paisagem virginal, ou praticamente intacta, que se mostrava disponível à intervenção alheia" (Martins, 2014, pp. 289, 283) que perpassam nas muitas imagens disseminadas pela metrópole.

Assim, as visões do império refletem, fundamentalmente, uma economia portuguesa florescente (através de fotografias de plantações, praças de comércio, caravanas, embarcações, etc.), bem como a afirmação do domínio português em terras africanas (através da valorização de edifícios, infraestruturas e benfeitorias coloniais). Não obstante, o exotismo dos povos autóctones e a categorização dos nativos na sua "estranheza" eram também motivos de interesse dos olhares ocidentais. A artista Michelle Henning refere a este propósito que "as fotografias não falam apenas dos corpos, mas de corpos em particular, de grupos sociais e de relações de poder entre eles" (2001, p. 247). O autor Michael Kohler reitera esta ideia, argumentando que "o que estas fotografias revelam, de facto, tem menos a ver com esses povos distantes, do que com os clichés ocidentais sobre o Outro esse Nobre Selvagem e o Primitivo Pérfido" (1986, p. 41).

Rapidamente, as ditas fotografias "etnográficas" entusiasmaram tanto cientistas, como o comum cidadão, que podiam, assim, descobrir como eram os "pretos". Refletindo amiúde a base racial e económica do domínio português, as fotografias coloniais portuguesas escondem, no entanto, o sistema do chibalo, ou o trabalho forçado, em que a exploração colonial se baseava (Ryan, 2014, p. 38), entre vários outros exemplos que denunciam o muito que se desconhecia do “império" e o seu carácter violento e discriminatório.

\section{4.- Fotografia colonial: Que lugar? Que futuro?}

Indubitavelmente, a fotografia enquanto registo "vivo" e palpável, objeto artístico ou documental, parte integrante de coleções de museus e instituições, espelho e guardiã de memórias, tem um valor patrimonial.

A fotografia colonial não é exceção, todavia a sua revisitação (tal como a manutenção do MAP na sua íntegra, como "museu de si próprio" [Leal, 2009]), implica uma atitude consciente e astuciosa, isto é, a sua "emolduração" e 
(re)enquadramento devem ser capazes de propor a reflexão, deixando claro que não se propõe uma atualização do discurso colonial. Atente-se nas palavras das antropólogas Sónia Vespeira de Almeida e Vera Marques Alves a respeito da preservação do MAP:

(...) também nós propomos a preservação do MAP, sugerindo a sua musealização de modo a dar a ver as ideias e valores que estiveram subjacentes à sua criação. O museu pode, assim, tornar-se não só um lugar de reflexão sobre as conotações ideológicas da arte popular durante o Estado Novo, mas também um instrumento decisivo para a compreensão de outras etapas do interesse intelectual e ideológico pela cultura demótica ao longo dos séculos XIX e XX. Em última instância, é a própria ânsia contemporânea pelo autêntico e pelo genuíno através do popular que pode ganhar um espaço ideal de interrogação crítica (2009, p. 469).

O antropólogo Paulo Ferreira da Costa argumenta que "independentemente da sua maior ou menor polissemia, os bens patrimoniais são invariavelmente objecto de um discurso específico e decorrente de um determinado contexto de intenções e contingências" devendo, por isso, ser vistos à luz do seu tempo (2009, p. 478). Neste contexto, receios ou eventuais ferimentos de suscetibilidades relativos à manutenção do MAP, ou à exposição de fotografias produzidas em períodos coloniais, revelam-se, na realidade, ocos.

Contudo, em Portugal parece existir uma tendência negligenciadora para com a fotografia colonial (como de resto com qualquer matéria relacionada com as políticas do Estado $\mathrm{Novo}^{5}$, ou qualquer outro assunto que incomode a ideia de pátria e interfira com o seu orgulho nacional), como se um sentimento de receio de lesapátria imperasse, levando a esconder e a abafar, ao invés de mostrar e expor e promover conversações, novos entendimentos e (re)interpretações da história (Cabecinhas e Nhaga, 2008, p. 111).

De facto, existe um vasto espólio de registos fotográficos "arrumados" nas gavetas das instituições, que aí permanecem "não tratados arquivisticamente", por explorar. É o caso, por exemplo, do álbum "photographico-litterario" da "Africa

\footnotetext{
${ }^{5}$ Regime político autoritário, instituído sob a direção de António de Oliveira Salazar, que vigorou em Portugal durante 41 anos, desde a aprovação da Constituição de 1933 até ao seu derrube pela Revolução de 25 de Abril de 1974.

Criar Educação, Criciúma, v. 7, n², jul/dez 2018.- PPGE - UNESC
} 
Occidental" de José da Cunha Moraes e F. de Salles Ferreira ${ }^{6}$. As suas fotografias comportam um evidente valor etnográfico, dado que Cunha Moraes foi um dos primeiros fotógrafos em África e este é considerado por António Sena (autor incontornável na história da fotografia portuguesa) um dos maiores fotógrafos do século XIX (1998, p. 107).

A historiadora Filipa Lowndes Vicente, reconhecendo as mais-valias da fotografia como objeto de estudo nas investigações pós-coloniais e a sua desvalorização por parte de algumas instituições e historiadores, manifesta-se assumidamente contra tal tendência. Observe-se a sua exposição:

\begin{abstract}
Os arquivos públicos e privados em Portugal estão cheios de materiais à espera de serem estudados criticamente. O mesmo sucede com os arquivos fotográficos existentes, hoje, nas ex-colónias portuguesas, a pesquisar em colaboração estreita com investigadores desses países. A historiografia e a teoria colonial das duas últimas décadas empreenderam um caminho em direcção aos arquivos, vozes e objectos existentes nos espaços que já foram colonizados. Há, de facto, que estudar o arquivo público e privado - da metrópole colonial mas há também que o colocar em diálogo com o arquivo, literal e metafórico, de São Tomé, Guiné, Moçambique, Macau, Angola, Timor, Índia e Cabo Verde (2014, p. 15).
\end{abstract}

Efetivamente, urge tratar a quantidade imensa de fotografias que residem relegadas ou esquecidas nas coleções de instituições como o Arquivo Histórico Ultramarino, o Museu Nacional de Etnologia, a Sociedade de Geografia de Lisboa, o Arquivo Nacional Torre do Tombo, entre outras, bem como alguns arquivos privados, empreendendo um trabalho em estreita negociação com investigadores das ex-colónias.

James R. Ryan, debruçando-se também sobre a importância do estudo das imagens fotográficas produzidas no período colonial, declara ainda que, quando expostas, não raras exceções, o uso de fotografias históricas de impérios coloniais europeus - em especial em África - apresenta um "quadro sentimental, enganador e, por vezes inteiramente falso, dos acontecimentos, indivíduos e circunstâncias históricos" (2014, p. 31).

Não obstante, segundo o historiador britânico, "tanto as representações

\footnotetext{
${ }^{6}$ Sobre este álbum veja-se Rocha \& Matos (no prelo).

Criar Educação, Criciúma, v. 7, n², jul/dez 2018.- PPGE - UNESC
} 
nostálgicas de um passado colonial pretensamente glorioso como as intensas críticas anticoloniais" tendem a encarar as fotografias como meros "adereços" ilustrativos de narrativas verbais (Ryan, 2014, p. 32). Deste modo, o autor (baseando-se nas conclusões do historiador Andrew Roberts) considera que, no decurso dos estudos realizados em torno das imagens coloniais, os temas das fotografias (fossem eles europeus ou africanos) foram, na maior parte das vezes, ingenuamente analisados "em modos muito genéricos e estereotipados", fazendose "poucos esforços para identificar o fotógrafo ou as circunstâncias em que a fotografia fora feita" (Ryan, 2014, p. 32).

Contudo, na opinião de Ryan, as fotografias que chegaram até aos nossos dias constituem "um dos registos mais cativantes e complexos da presença colonial europeia em África entre meados do século XIX - quando surgiu o medium fotográfico - e a segunda metade do século $X X$, quando sucessivas vagas de descolonização se espalharam pelo continente" (2014, p. 31). Durante este período, que durou mais de cem anos, vários fotógrafos profissionais e amadores envergaram máquinas fotográficas com o intuito de registar as suas experiências enquanto colonos, soldados, funcionários governamentais, missionários e, até mesmo, súbditos colonizados (Ryan, 2014, p. 31). Numa era de positivismo, a fotografia parecia oferecer aos seus praticantes, bem como a quem as percecionava, a possibilidade de criarem e idealizarem imagens "reais" e "objetivas" de pessoas e locais estranhos e desconhecidos. Assim, as câmaras fotográficas rapidamente passaram a ser usadas por uma panóplia variada de figuras da cena colonial sedentas de captarem e imortalizarem as suas vivências e encontros. Analisar estes registos fotográficos heterogéneos pode revelar-se, portanto, uma forma profícua e multifocal de explorar a história e os legados do colonialismo e dos imperialismos ocidentais.

$\mathrm{Na}$ realidade, a fotografia colonial não se associa apenas ao aglomerado de fotógrafos profissionais comissionados pelas nações imperiais. Amadores, médicos, exploradores e etnógrafos foram expeditos no embargo do novo meio para registar as suas aventuras e os seus contactos com gentes e locais "exóticos" e longínquos. Do mesmo modo, os soldados (não obstante a ideologia luso-tropicalista e a Criar Educação, Criciúma, v. 7, n², jul/dez 2018.- PPGE - UNESC 
considerada "expansão extracontinental que se fez mais com o coração do que com a espada" [Carmona, 1940, p.10]), também usaram as câmaras fotográficas para registar atividades militares e campanhas de ocupação, sobretudo em Angola e Moçambique, entre a década de 90 do século XIX e os anos 20 do século XX. Tais registos figuram em muitas coleções particulares feitas por oficiais do exército português (Ryan, 2014, p. 38).

As relações entre a fotografia e os impérios revelam-se imensas e com múltiplas dimensões. Não obstante, a maior parte das fotografias, quer profissionais, quer amadoras, realizadas nos territórios coloniais "foi feita por, e para, europeus ou americanos" e por isso tende "a servir os interesses e as prioridades de quem as fazia e de quem as via" (Ryan, 2014, p. 39).

Crucial na construção e manutenção de um império imaginário, a fotografia, através dos seus múltiplos usos, procurou edificar uma nação imperial imaginada, que se concebia e apercebia como real, mediante imagens que "ilustravam" territórios remotos; espelhavam maravilhas naturais; legitimavam hierarquias rácicas e de poder; aplaudiam atos civilizadores e colonizadores e celebravam a grande nação ultramarina que era Portugal. É o que acontece, por exemplo, com: o álbum fotográfico África Occidental de Cunha Moraes (1882); a obra Raças do Império de Mendes Correia (1943); e os dois volumes, profusamente ilustrados, intitulados Outras Terras, Outras Gentes de Henrique Galvão (1944-1947).

Com o advento das tecnologias digitais, da Internet e da digitalização de coleções, as fotografias dos impérios modernos tornam-se acessíveis a um público mais vasto e global. A tecnologia digital pode acarretar, deste modo, um prenúncio de abertura desses registos a novos públicos, impulsionando novas reinterpretações e até "repatriando" as fotografias dos arquivos na metrópole, em capitais europeias, para os antigos territórios coloniais onde foram produzidas (Ryan, 2014, p. 41).

Todavia, embora inúmeras fotografias estejam a ser expostas a novos públicos, muitas das imagens fotográficas do império permanecem invisíveis, devido à "extrema incapacidade dos museus de integrarem passados nacionais coloniais nas suas próprias narrativas" (Ryan, 2014, p. 42). Portugal parece também não ter Criar Educação, Criciúma, v. 7, n², jul/dez 2018.- PPGE - UNESC 
sabido ainda incorporar o seu passado colonial, a não ser reproduzindo os mesmos discursos imperialistas de forma dissimulada, atualizando-os em comemorações como a dos 500 anos da "descoberta" do Brasil ou a dos 600 anos da tomada de Ceuta (Almeida, 2002,p. 29).

Com efeito, nas sociedades atuais, pós-coloniais e multiculturais, as fotografias históricas produzidas durante o período áureo dos "impérios" europeus "ainda contêm um poder incómodo", subsistindo em razão disso muitas questões quanto ao modo como curadores de museus e historiadores devem preservar e expor representações visuais do "império" aos públicos do século XXI (Ryan, 2014, p. 42).

Neste âmbito, defende-se que urge hoje uma mudança de atitude por parte de curadores, agentes culturais, políticos e públicos, que seja capaz de olhar para a fotografia colonial de forma crítica, vendo nela um potencial para inquirir sobre as complexidades do passado. Acredita-se, assim, que impera a necessidade de manter este legado fotográfico "vivo", para que se possam conferir novos significados à fotografia colonial, bem como ao imperialismo e às suas reminiscências.

\section{Considerações Finais}

Segundo a conceção clássica, o património refere-se "ao legado que herdamos do passado e que transmitimos a gerações futuras" (Peralta, 2000, p. 9). Não obstante, os processos de patrimonialização e musealização de elementos materiais e imateriais encontram-se relacionados com as questões de poder e com um conjunto de agentes que decide sobre o que legar às gerações vindouras, de acordo com a sua subjetividade e agendas políticas.

Neste contexto, parece haver uma tendência essencialista nos discursos identitários nacionais que procura a univocidade cultural e a homologação de uma história e um passado que se distinguem pela sua "grandiosidade" e "originalidade". Esta constante busca pela afirmação de uma identidade baseada na grandeza e na autenticidade dificulta o tratamento de questões incómodas, nomeadamente, a 
colonial.

Na aceção de vários autores, uma nação é uma comunidade simbólica que cria "alianças fortes - por vezes, patológicas - em redor de um ideal cultural e de um ideal de modo de vida" (Boswell e Evans apud Almeida, 2004, p. 6). Existe, por isso, uma espécie de sentimento de lesa-pátria que nebula o que celebrar e salvaguardar em matérias patrimoniais referentes ao período colonial. Efetivamente, em Portugal, perante a edificação de uma nação e respetiva identidade ancorada nas "Descobertas", tem-se optado por ocultar a maleficência da colonização lusitana, e tal não é exceção na patrimonialização desse passado.

Posto isto, a questão que se coloca é: como devem ser tratadas, então, as fotografias coloniais? Que destino merecem estes géneros patrimoniais?

A patrimonialização do passado colonial não é, de facto, um assunto fácil; contudo, defende-se que os legados culturais não devem ser encarados como fenómenos passivos, mas como processos dinâmicos. De acordo com o que foi explanado ao longo deste artigo, entende-se, assim, que o património é algo vivo, mutável e atualizável no quotidiano das comunidades, dependendo, por isso, não só do que se herda, mas também da forma como essa herança é recebida e incorporada na sociedade.

As nações, apesar de tenderem a assentar as suas bases identitárias em pilares de estabilidade e perpetuação histórica, têm a capacidade de desenvolver novas e alternativas narrativas, que sejam hábeis em abandonar configurações passadistas. Ora, os museus, as galerias de exposições e outros locais históricos, enquanto "agências civilizadoras e educativas" (Bennet apud Almeida, 2004, p. 6) e montras de inventários simbólicos da identidade portuguesa, têm um papel preponderante a desempenhar neste sentido, devendo, por isso, empenhar-se na construção de um discurso identitário reformulado.

Não há dúvidas que a fotografia produzida em contexto colonial, na sua maioria, serviu uma identidade colonialista, ajudando a criar simbolicamente uma nação "imperial”. A musealização destes objetos é, por isso, um assunto complexo. Todavia, uma reflexão sobre o lugar da fotografia colonial no contexto do património nacional português mostra que os museus e as demais instituições culturais têm Criar Educação, Criciúma, v. 7, n², jul/dez 2018.- PPGE - UNESC 
negligenciado estas imagens, pela extrema dificuldade em integrar o passado colonial nas suas coleções, optando por esconder ao invés de mostrar (e quando optam por expor, nem sempre a sua mensagem é clara, verificando-se uma reprodução dos discursos imperialistas de forma dissimulada, muitas vezes assente em representações nostálgicas de um passado supostamente glorioso).

Neste âmbito, o presente artigo pretende ser um alerta sobre o precário estado em que a fotografia produzida em contexto colonial se encontra, defendendo que, independentemente da intencionalidade que the deu origem, enquanto objeto artístico, etnográfico e histórico, ela deverá ter um valor patrimonial e, portanto, um lugar à sua espera nos arquivos e nos museus. Para que tal aconteça, contudo, a sua recontextualização deve ser feita, inequivocamente, no sentido da demarcação do discurso colonialista e não de uma dissimulada atualização do mesmo. 


\section{CRIAR EDUCAÇÃO \\ Revista do Programa de Pós-Graduação em Educação - UNESC}

\section{Referências}

ALMEIDA, J. C. A Memória e Identidade Nacional: As Comemorações Públicas, As Grandes Exposições e o Processo de (re)construção da Nação. VIII Congresso Luso-Afro-Brasileiro de Ciências Sociais, CES - Centro de Estudos Sociais da Universidade de Coimbra, 2004. Disponível em:

http://www.ces.uc.pt/lab2004/pdfs/JoseCarlosAlmeida.pdf, Acesso em: 07 Agosto 2015.

ALMEIDA, M. V. de Um mar da cor da terra: raça, cultura e política da identidade. Oeiras: Celta, 2002.

ALMEIDA, S. V. de; ALVES, V. M. Uma proposta antropológica para o futuro do Museu de Arte Popular. Etnográfica, 2009, vol. 13, no.2, p. 467-472.

CABECINHAS, R.; NHAGA, N. Memórias e diálogos pós -coloniais: Guiné -Bissau e Portugal. In: CABECINHAS, R.; CUNHA, L. (eds) Comunicação intercultural: Perspectivas, dilemas e desafios. Porto: Campo das Letras Editores, 2008.

CAHEN, M. Portugal is in the Sky: Conceptual considerations on communities, lusitanity and lusophony. Nova lorque: Palgrave Macmillan, 2013.

CARMONA, Ó. Palavras do Chefe de Estado na Câmara Municipal de Lisboa a 2 de Junho de 1940. Revista dos Centenários, 30 Junho 1940, n 18, Ano II, p. 710.

CHOAY F. A Alegoria do Património. Lisboa: Edições 70, 1992.

COSTA, P. F. da. Museu de Arte Popular: oportunidades perdidas, novas oportunidades. Etnográfica, 2009, vol.13, no.2, p. 477-480.

CUNHA, F. I. Identidade e Reconhecimento nos Media. Matrizes, 2007, vol.1, no.1, p. 187-208.

Diário da República, Decreto-Lei n. 139/2009, Disponível em: http://www.unesco.org/culture/natlaws/media/pdf/portugal/portugal lei139 2009 pororof.pdf Acesso em: 10 Agosto 2015.

GONÇALVES, A. O ceptro e a máscara. Discursos de identidade, reificação e poder, In: GONÇALVES, A. (org). Vertigens: Para uma sociologia da perversidade. Coimbra: Grácio Editor/ CECS Universidade do Minho, 2009.

HENNING, M. The subject as object: photography and the human body. In: WELLS, L. (ed)

Criar Educação, Criciúma, v. 7, n², jul/dez 2018.- PPGE - UNESC 
Photography: A Critical Introduction. London e New York: Routledge, 2001.

HENRIQUES, I. C. Os africanos na sociedade portuguesa: Formas de integração e construção de imaginários (séculos XV-XX), Inventário de Problemáticas. In: RODRIGUES, D.; RODRIGUES, C. (eds)

Representações de África e dos Africanos na História e Cultura: Séculos XV a XXI. Ponta Delgada: CHAM - Universidade de Lisboa/ Universidade dos Açores, 2001.

HUYSSEN, A. Seduzidos pela Memória: Arquitectura, Monumentos, Mídia. Rio de Janeiro: Aeroplano, 2000.

KOHLER, M. The Body Exposed: Views of the body, 150 years of the nude in photography. Zurich: Editions Stemmale, 1986.

KOSSOY, B. Fotografia e História. São Paulo: Ateliê Editorial, 2001.

LEAL, J. Da arte popular às culturas populares híbridas. Etnográfica, 2009, vol. 13 , no. 2, p. 467-480.

LOURENÇO, E. A Morte de Colombo: Metamorfose e fim do Ocidente como mito. Lisboa: Gradiva, 2005.

LOWENTHAL, D. Identity, Heritage and History. Princeton: Princeton University Press, 1994.

MAGALHÃES, F. Museus, Património e Identidade: Ritualidade, Educação, Conservação, Pesquisa, Exposição. Leiria: Profedições, 2005.

MARTINS, L. P. Imaginar o império através da revista ilustrada O Ocidente (1878 - 1915). In: VICENTE, F. L. (org) O Império da Visão: Fotografia no Contexto Colonial Português (1860-1960). Lisboa: Edições 70, 2014.

NORA, P. Les Lieux de Mémoire. Paris: Gallimard, 1989.

ORTIZ, R. Cultura Brasileira \& Identidade Nacional. São Paulo: Editora Brasiliense, 2006.

PACHECO, H. Rostos da Gente. Lisboa: Caminho, 1987.

PERALTA, E. Património e Identidade: Os Desafios do Turismo Cultural. Antropológicas, 2000, no. 4. Disponível em: http://revistas.rcaap.pt/antropologicas/article/viewFile/932/734 Acesso em: 10 Agosto 2015.

PERALTA, E. O Mar por Tradição: o património e a construção das

Criar Educação, Criciúma, v. 7, n², jul/dez 2018.- PPGE - UNESC 
imagens do turismo. Horizontes Antropológicos, 2003, no. 20, p. 83-96.

PERALTA, E.; ANICO, M. (org.) Patrimónios e Identidades: Ficções

Contemporâneas. Oeiras: Celta Editora, 2006.

PERALTA, E.; ANICO, M. Heritage and Identity: Engagement and Demission in the Contemporary World. Londres e Nova lorque: Routledge, 2009.

PGDL (Procuradoria-Geral Distrital de Lisboa), Lei $n .$. 107/2001, de 08 de Setembro: Lei de Bases do Património Cultural. Disponível em: http://www.pgdlisboa.pt

Acesso em: 10 Agosto 2015.

PRATS, L. Antropología y Patrimonio. Barcelona: Ariel, 1997.

ROCHA, L. O. da; MATOS, P. F. de. Ver para crer? Desafios educacionais sobre o poder da fotografia, Revista Práxis Educacional, 2018, vol. 14, no. 29, p. 177197.

ROCHA, L. O. da; MATOS, P. F. de. Fotografias de Angola do século XIX: 0 'Álbum Fotográfico-Literário' de Cunha Moraes. Tempos e Espaços em Educação, Universidade Federal de Sergipe (no prelo).

RYAN, R. J. Introdução: Fotografia Colonial. In: VICENTE, F. L. (org) 0 Império da Visão: Fotografia no Contexto Colonial Português (18601960). Lisboa: Edições 70, 2014, p. 31-42.

SENA, A. História da Imagem Fotográfica em Portugal, 1839-1997. Porto: Porto Editora, 1998.

URRY, J. How societies remember the past. In: MACDONALD, S.; FYFE, G. (eds) Theorizing Museums: Representing Identity and Diversity in a Changing World. Oxford: Blackwell Publishers, 1996.

VICENTE, F. L. (org) O Império da Visão: Fotografia no Contexto Colonial Português (1860-1960). Lisboa: Edições 70, 2014.

VIEIRA, R. Prefácio. In: MAGALHÃES, F. Museus, Património e Identidade: Ritualidade, Educação, Conservação, Pesquisa, Exposição. Leiria: Profedições, 2005.

Recebido em fevereiro 2018

Aprovado em outubro 2018

Criar Educação, Criciúma, v. 7, n², jul/dez 2018.- PPGE - UNESC 